\title{
The efficacy of hearing aids for emotional and auditory tinnitus issues
}

Jamile Cabral ${ }^{1}$

Rita Tonocchi ${ }^{1}$

Ângela Ribas

Gleide Almeida

Marine Rosa ${ }^{2}$

Giselle Massi ${ }^{1}$

Ana Paula Berberian ${ }^{1}$

\begin{abstract}
Introduction: The use of hearing aids has been one of the strategies to reduce tinnitus perception and improve sufferers' quality of life when this symptom is associated to hearing impairment. Objective: To assess the remission of emotional and auditory tinnitus impacts on users of hearing aids. Methods: It is an experimental, descriptive study carried out with 17 users of unilateral or bilateral hearing aids, reporting tinnitus, submitted to otorhinolaryngological screening, tonal audiometry, logoaudiometry and acoustic imittance testing, who also answered the lowa Tinnitus Activities Questionnaire, as well as the lowa Tinnitus Handicap Questionnaire. Results: There was significant difference in tinnitus data scoring before the use of hearing aids and after fitting the hearing aids. Conclusion: Analysis of the results evidences that the use of hearing aids improves tinnitus patients' quality of life, mainly regarding their emotional and auditory aspects.
\end{abstract}

Keywords: tinnitus, hearing loss, hearing aids, quality of life.

\footnotetext{
${ }^{1}$ Programa de Pós-Graduação em Distúrbios da Comunicação, Universidade Tuiuti do Paraná, Curitiba, PR, Brazil. E-mail: jamilli-2@hotmail.com / ritacato@hotmail.com / angela.ribas@utp.br / gleidevivi@gmail.com / giselle.massi@utp.br / ana.silva17@utp.br

${ }^{2}$ Master's Program in Neuroscience and Behavior - University Federal of Paraíba, João Pessoa, PB, Brazil. E-mail: mrdrosa@yahoo.com.br

Institution: Universidade Tuiuti do Paraná

Send correspondence to:

Rita Tonocchi

Rua Cândido Xavier, 1426, apt. 11 B, Vila Izabel. Curitiba, PR, Brazil. CEP: 80320-220.

Paper submitted to the RBCMS-SGP (Publishing Management System) on March 28, 2016;

and accepted on April 4, 2016. cod. 235
} 


\section{INTRODUCTION}

Tinnitus, also defined as a phantom sound, is a symptom that may be related to over two hundred ear or systemic illnesses ${ }^{1,2}$, and can disturb people's sleep, concentration, emotional balance and social interaction ${ }^{3,4}$. The complexity of its physiopathology and the significant degree of subjectivity concerning tinnitus, raise questions on this symptom which are far from being answered. As it is unfeasible to evaluate it in an objective way, and the fact that it can be a symptomatic effect of several illnesses, generate variables which make it difficult to provide a clear explanation for tinnitus, thus reducing experts' interest in studying the so-called phantom sound ${ }^{5,6}$.

Tinnitus is known to hinder sufferers' quality of life as well as their families', bringing about severe emotional disorders. Studies show that, in extreme cases, such disturbances may lead people to commit suicide. Lewis et al. ${ }^{7}$ reports the cases of 28 patients who committed suicide due to tinnitus, pointing out the significant prevalence of elderly, male individuals with social withdrawal among the risk factors. Johnston and Walker ${ }^{8}$ also studied suicidal patients of psychiatric clinics, featuring them as people who suffered from untreatable tinnitus, communication impairment and hopelessness as common specificities among the researched subjects. Thus, it should be pointed out the fundamental role of a multidisciplinary team in the assessment, diagnosis and development of intervention strategies as well as treatment of patients suffering from tinnitus ${ }^{9}$.

Concerning, more specifically, the association between tinnitus and hearing loss, it is possible to state that it has been extensively described in the literature. According to different reports, 85 to $96 \%$ of patients with tinnitus feature some degree of hearing loss ${ }^{10}$, and only 8 to $10 \%$ feature normal audiometry ${ }^{11}$. Studies on the treatment of patients with tinnitus point to hearing aids as a therapeutic option. In some cases, the mere amplification of environmental noise covers up or significantly reduces tinnitus perception, providing immediate relief; in other cases, such relief is slower and more gradual in order to facilitate the neurophysiological process ${ }^{12}$.

Tinnitus masking, initially performed by Jack Vernon, consists of using sound emission devices, and has been used since the 1970s aiming at patients' relief from tinnitus effects. This masking can be total, the complete tinnitus cover up, or partial, reducing its intensity ${ }^{13}$.

There is an increasing number of approaches to develop and test efficient treatments for tinnitus relief. As this symptom may stem from innumerable conditions of physical impairment, there is certainly not a single treatment for all types of tinnitus. Tinnitus Retraining Therapy (TRT) was developed from tinnitus "neurophysiological model", described by Jastreboff' ${ }^{14}$, aiming at promoting the habituation of tinnitus-induced responses and tinnitus perception ${ }^{15}$. Therefore, TRT does not aim at eliminating tinnitus, but it objectifies to reduce individuals' tinnitus perception by weakening the connections between the auditory system and limbic, autonomous nervous system, responsible for the annoyance that features tinnitus. TRT is an alternative to facilitate habituation by means of two basic principles: therapeutic counseling and sound enrichment.

Therapeutic counseling, according to Mckinney et al. ${ }^{16}$, is the most important principle in TRT, and objectifies to remove tinnitus negative associations. It consists of reviewing and explaining the results of audiological and physiological testing, auditory processing information in central nervous system, and their relation to tinnitus. The counseling sessions aim to intervene on the way patients perceive tinnitus and their ear system, although they do not intervene directly in patients' psychological aspects ${ }^{17}$.

The second principle, known as sound enrichment, objectifies to facilitate the habituation of tinnitus perception by reducing the difference between tinnitusrelated neural activity and background neural activity. Patients featuring tinnitus and clinically significant hearing impairment, sound enrichment is provided by amplifying environmental sounds of low intensity through hearing aids ${ }^{18}$. Those sounds gradually reduce the attention focus on tinnitus, thus inducing the retraining process ${ }^{19}$. Tinnitus maskers have frequently been used in order to cover up the tinnitus. This treatment promotes fast reduction of the tinnitus, although in many cases, patients keep perceiving it after removing the hearing aid, not being expected any medium or long-term relief.

Some studies suggest the adoption of four criteria for fitting hearing aids in the presence of tinnitus: the use of well-ventilated designs ${ }^{20,21}$; the use of retroauricular hearing aids ${ }^{4}$; bilateral hearing-aid fitting whenever it is possible ${ }^{20}$; continuous use of hearing aids ${ }^{22}$.

Thus, keeping in mind the association between tinnitus and hearing loss, and considering the need to describe groups of subjects featuring tinnitus and clinically significant hearing impairment, this study objectifies to assess the remission of tinnitus emotional and auditory impacts on hearing-aid users.

\section{METHODS}

It is an experimental, descriptive study approved by the Ethics Committee CEP/UTP027/08, which entailed 17 individuals with tinnitus complaint, who signed the Free Informed Consent Form. Participants should feature hearing impairment with tinnitus complaint, and use unilateral or bilateral hearing aids to be included in the study. 
All patients underwent otorhinolaryngological screening, and were submitted to tonal audiometry, logoaudiometry and acoustic imittance testing.

Subsequently, they answered two questionnaires: a) IowaTinnitus Activities Questionnaire (TAQ), applied before hearing-aid fitting; b) lowa Tinnitus Handicap Questionnaire (THQ) ${ }^{23}$, applied about three months after hearing-aid fitting.

TAQ assesses aspects related to concentration, emotion and hearing. It comprises 20 questions, and is numbered according to questions about the tinnitus perception after the use of hearing aids. Questions 1, 5, 7, 16 and 20 Questions 3, 8, 13,15 and 18 assess tinnitus effects on emotional issues. Questions 6, 9, 10, 12 and 19 assess tinnitus effects on hearing. Finally, questions $2,4,11,14$ and 17 assess tinnitus effects on sleep.

THQ comprises 27 numbered questions regarding tinnitus perception before the use of hearing aids. Questions 4, 7, 9, 11, 13, 14, 15, 16, 17, 18, 19, 23, 24, 25 and 27 assess tinnitus effects on social, emotional and behavioral issues (factor 1). Questions 2, 6, 10, 12, 20, 21, 22 and 26 assess tinnitus effects on hearing. And questions 3, 5, 8 and 1 assess patients' tinnitusrelated perspectives. In the light of this study objective, which is to assess tinnitus remission and its emotional and auditory impacts on users of hearing aids, patients' answers to the applied questionnaires were considered, mainly the ones related to the emotional and auditory perceptions caused by the tinnitus before and after the use of hearing aids. That is why, THQ questions 13 , $14,15,16,17,18,19$ and 27 (applied before the use of a hearing aid), regarding emotional aspects were particularly analyzed, and compared to TAQ questions $3,8,13,15$ and 18 , related to emotional characteristics, applied after hearing-aid fitting. Moreover, patients' answers were analyzed in relation to tinnitus and hearing perception in THQ questions 2, 6, 10, 12, 20, 21, 22, 26 (before the use of hearing aids), comparing them to TAQ hearing questions 6, 9, 10,12 and 19.

Both questionnaires analyze several other questions regarding tinnitus, such as concentration and sleep, besides behavioral aspects. The answers that participants in the current research provided to those questions were used to expand the discussion around the main theme in this study, which is emotional and auditory perceptions related to tinnitus.

Concerning the application of the questionnaires to the participants, the researcher read each question to each interviewee. Whenever the patient showed any difficulties, the question was repeated by the interviewer, and most of the time, reformulated for better understanding. To both questionnaires, patients answered 0 (zero) if they strongly disagreed, and 100, if they strongly agreed with the question. Total scoring, as well as the scores of each analyzed aspect were computed. Thus, the highest possible total scoring is considered to correspond to 100 , evidencing the maximum disturbance in patients' quality of life due to tinnitus. On the other hand, the lowest possible scoring totals 0 points, not evidencing any losses in the quality of life of individuals with hearing impairment and associated tinnitus complaint.

Data were uploaded in an electronic sheet, and analyzed through Wilcoxon's statistical analysis, $p<0.05$.

\section{RESULTS}

From the 17 participants in the current research, 13 were female, and 4 were male. Age ranged 26 to 87 years old, mean age of 57 years old.

All participants were hearing impaired, and data for type and degree of the hearing loss are reported in Table 1. Regarding the configuration of the hearing loss, 3 were flat, 8 were descending, 5 were sloping, and only one had an irregular audiometric configuration.

Table 1. Description of the sample according to the hearing loss $(\mathrm{n}=17)$

\begin{tabular}{lcc}
\hline & $\begin{array}{c}\text { Sensorineuralhearing loss } \\
(\mathrm{n}=13)\end{array}$ & $\begin{array}{c}\text { Mixed } \\
\text { hearing loss }(\mathrm{n}=4)\end{array}$ \\
\hline Mild degree & 5 & 1 \\
Moderate degree & 5 & 2 \\
Moderate-severe & 3 & 0 \\
degree & 0 & 1 \\
Severe degree & 13 & 4 \\
Total & & \\
\hline
\end{tabular}

Etiological diagnosis of the hearing loss is undefined in nine subjects, three were determined by heredity, one by neurinoma, one patient due to infectious disease, one due to emotional factor, and two reported other causes.

In the current study, only one participant wears unilateral hearing aid, all the others wear bilateral hearing aids, $100 \%$ digital fitting. As for the model, $46 \%$ use intracanal hearing aids, and $54 \%$ make use of retroauricular open-fit hearing aids.

Bilateral tinnitus is perceived by $88 \%$ of the sample. Regarding tinnitus perception, $41 \%$ are sporadic, while $58 \%$ are persistent, and $52 \%$ refer to a whistling-like noise, $12 \%$ to a cricket-like noise, $12 \%$ to a waterfall-like noise, and $24 \%$ to other types of noise.

Table 2 describes the results from the THQ, before the use of hearing aids, and Table 3 describes the results from the TAQ, applied after the use of hearing aids.

Table 4 describes the comparison of score results, considering the emotional and auditory perception related to tinnitus. By applying Wilcoxon statistical test, $p<0.05$, it is possible to state a significant difference in the score results for tinnitus-related data before the use 
Table 2. THQ results before the use of hearing aids $(n=17)$.

\begin{tabular}{lccc}
\hline & Concentration & Emotion & Hearing \\
\hline Mean Scoring & $37 \%$ & $35 \%$ & $41 \%$ \\
Standard Deviation & 8.37 & 3.47 & 9.27 \\
\hline
\end{tabular}

Table 3. TAQ results after the use of hearing aids.

\begin{tabular}{lcclc}
\hline & Concentration & Emotion & Hearing & Sleep \\
\hline Mean Scoring & $23 \%$ & $26 \%$ & $25 \%$ & $4 \%$ \\
Standard Deviation & 3.79 & 1.42 & 2.16 & 1.11 \\
\hline
\end{tabular}

of hearing aids and after fitting the hearing aids. In both aspects considered in the present study, there was a significance level of $p<0.05$. As for tinnitus related to patients' emotional aspect, statistical analysis evidenced $p=0.0131$. Regarding the association of tinnitus to patients' hearing, $p=0.0158$.

Table 4. Comparison of results before and after the use of the hearing aids.

\begin{tabular}{lcccc}
\hline COMPARISON & $\mathrm{N}$ & T STATISTICS & z STATISTICS & $p$ \\
\hline Tinnitus/Emotional & 17 & 10.0 & 2.481 & $0.0131^{*}$ \\
Tinnitus/Hearing & 17 & 25.5 & 2.414 & $0.0158^{*}$ \\
\hline
\end{tabular}

\section{DISCUSSION}

Age and gender ranges varied significantly in the sample (between 26 and 87 years old), which evidences that hearing impairment and tinnitus are not exclusive symptoms from a certain age range. Etiology was also varied, which confirms the fact that tinnitus is a symptom that can be present in the most varied phases of life, and does not usually follow defined etiologies ${ }^{1,24}$. Assessing and identifying the kind of tinnitus can be relevant to select the suitable therapy².

Although the sample comprises hearing-impaired people, prevailing mild to moderate sensorineural hearing loss, tinnitus does not necessary follow hearing losses, fact which was not studied in this research ${ }^{11}$. Hearing aids were the selected therapy by the studied group, in agreement with the searched studies ${ }^{4}$. The majority of the sample, due to the reported complaints, uses bilateral fitting hearing aids, and literature claims to be the ideal fitting, as symmetric stimulation is fundamental for the process of tinnitus habituation ${ }^{14}$.

It was also evidenced that most subjects use retroauricular open-fit hearing aids, in agreement with studies $^{14,21}$ which state that the occlusion of the ear external canal must be avoided, as this may increase tinnitus perception. The use of ventilated ear designs enables the passage of environmental, non-amplified, low-frequency sounds, favoring the habituation process. Thus, the retroauricular hearing aid is the model which enables the most varieties in the size of the ventilation design, and the best fittings for frequency gain and response ${ }^{24}$.

The results of the questionnaires unveil that tinnitus is perceived in a negative way by the sample. As for tinnitus effects on social, emotional and behavioral interaction, a prevalence of negative answers is verified in $37 \%$ of the patients. Research ${ }^{25}$ studying a group of elders observed worse performance in tests of quality of life, ultimately due to emotional issues. As for hearing, it pointed to the lowest average found, that is, around $35 \%$.

This study is in conformity with research studies on tinnitus-related difficulties in specific activities, such as sleep and concentration problems ${ }^{25-28}$. Even with the use of hearing aids, it was possible to analyze persistent complaints on concentration and sleep disturbance, although they were reported by less than $23 \%$ of the interviewees.

The analysis that considers the tinnitus relation to patients' emotional aspects by comparing scoring of the answers provided to the questionnaires on the tinnitus sensation before and after the use of hearing aids, points to significant improvement with the use of hearing aids. Therefore, mean scores are significantly lower after hearing-aid fitting, evidencing the efficacy of hearing aids in patients reporting tinnitus, mainly in relation to their emotional and hearing aspects. The relation between tinnitus and emotional aspects (depression, anxiety) is well described ${ }^{6}$, although it is difficult to establish which is the cause or the effect, thus it is essential to treat the symptom.

Therefore, the use of hearing aids for patients with tinnitus complaint may promote improvement in those individuals' quality of life, to the extent that they report better perception of their hearing skills, as well as in aspects related to their emotional status. The need to carry out more research studies on this theme should be pointed out, which expand the number of participants and deepen data collection methods so that new results can be confronted and discussed, fostering assessment, diagnosis and therapy to people who suffer from tinnitus associated with hearing losses.

\section{CONCLUSION}

Analysis of the results evidences that the use of hearing aids promotes the improvement in the quality of life of patients with tinnitus, ultimately in emotional and auditory aspects.

\section{REFERENCES}

1. Sanchez TG, Bento RF, Miniti A, Câmara J. Zumbido: características e epidemiologia. Experiência do Hospital das Clínicas da Faculdade de Medicina da Universidade de São Paulo. Rev Bras Otorrinolaringol. 1997;63(3):229-35. 
2. Sanchez TG, Bento RF. An evaluation of tinnitus treatment Comments on the literature and a personal point of view. Exp Opin Ther Patents. 2000;10(12):1911-7.

3. Sanchez TG. Reabilitação do paciente com zumbido. In: Campos CA, Costa HO. Tratado de Otorrinolaringologia da Sociedade Brasileira de Otorrinolaringologia. São Paulo: Rocca; 2002. p.31124.

4. Sanchez TG, Ferrari GMS. O controle do zumbido por meio de prótese auditiva: sugestões para otimização do uso. Pró-Fono. 2002;14(1):111-8.

5. Sanchez TG, Ferrari GMS. Preliminary experience with tinnitus retraining therapy in Brazil. In: Patuzzi R, ed. Proceedings of the Seventh International Tinnitus Seminar; 2002 Mar 5-9; Perth, Australia. p.182-5. p.263-5.

6. Coelho CCB, Sanchez TG, Bento RF. Características do zumbido em pacientes atendidos em serviço de referência. Arq Int Otorrinolaringol. 2004;8(3):216-24.

7. Lewis JE, Stephens SD, McKenna L. Tinnitus and suicide. Clin Otolaryngol Allied Sci. 1994;19(1):50-4.

8. Johnston M, Walker M. Suicide in the elderly. Recognizing the signs. Gen Hosp Psychiatry. 1996;18(4):257-60.

9. American Academy of Audiology. Audiologic Guidelines for Diagnosis and Management of Tinnitus Patients [cited 2016 Apr 28] Available from: http://www.audiology.org/publications-resources/ document-library/audiologic-guidelines-diagnosis-managementtinnitus-patients

10. Fowler EP. Head noises in normal and in normal and disordered ears: significance, measurement, differentiation and treatment. Arch Otolaryngol. 1994;39(6):498-503

11. Barnea G, Attias J, Gold S, Shahar A. Tinnitus with normal hearing sensitivity: extended high-frequency audiometry and auditory-nerve brain-stem-evoked responses. Audiology. 1990;29(1):36-45.

12. Martin WH, Fomer RL, Shi YB. Assistive Tinnitus devices and delivery methods for acoustical therapy. In: Patuzzi R, ed. Proceedings of the Seventh International Tinnitus Seminar; 2002 Mar 5-9; Perth, Australia. p.182-5.

13. Vernon JA, Meikel MB. Tinnitus Masking. In: Tyler RS, ed. Tinnitus handbook. San Diego: Singular Publishing; 2000. p.313-56.

14. Jastreboff PJ. Phantom auditory perception (tinnitus): mechanisms of generation and perception. Neurosci Res. 1990;8(4):221-54.

15. Jastreboff PJ, Hazell JW. A neurophysiological approach to tinnitus: clinical implications. Br J Audiol. 1993;27(1):7-17.

16. Mckinney CJ, Hazell JWP, Graham RL. Changes in loudness discomfort level and sensitivity to environmental sound with habituation based therapy. In: Hazell JWP, ed. Proceedings of the Sixth International Seminar; 1999 Sep 5-9; Cambridge, UK. p.499591.

17. Zofio E, Rubio L, Heitzmann T, Cardenas, MR. Basic differences Between directive counseling in TRT and cognitive strategies in psychotherapy: On illustrative case. In: Hazell JWP, ed. Proceedings of the Sixth International Seminar; 1999 Sep 5-9; Cambridge, UK. p.507-8.

18. Jastreboff PJ. Optimal sound use in TRT: theory and oractuce. In: Hazell JWP, ed. Proceedings of the Sixth International Seminar; 1999 Sep 5-9; Cambridge, UK. pg.32-8.

19. Jastreboff PJ, Jastreboff MM. Tinnitus retraining therapy. Semin Hear. 2001; 22(1):51-64.

20. Bartnik G, Fabijanska A, Rogowski M. Our experience in treatment of patient with tinnitus and/or hyperacusis using the habituation method. In: Hazell JWP, ed. Proceedings of the Sixth Internacional Seminar; 1999 Sep 5-9; Cambridge, UK. p.415-7.

21. Gold S, Gray WC, Hu S, Jastreboff PJ. Selection and fitting of noise generators and hearing aids for tinnitus patients. Proceedings of the Fifth International Tinnitus Seminar; 1995 Jul 12-16; Portland, USA. p.312-5.

22. Henry JA, Schechter MA, Nagler SM, Fausti SA. Tinnitus retraining therapy and tinnitus masking: How do they compare? In: Patuzzi $\mathrm{R}$, ed. Proceedings of the Seventh International Tinnitus Seminar; 2002 Mar 5-9; Perth, Australia. p.247-54.

23. Coelho C. Tinnitus Activities Questionaires [cited $2012 \mathrm{Ju}$ 3]. Available from: http://www.uihealthcare.com/depts/med/ otolaryngology/clinics/tinnitus/questionnaires/translations. html\#Portuguese

24. Samelli AG. Zumbido. Avaliação, diagnóstico e reabilitação: abordagens atuais. São Paulo: Lovise; 2004. p.23-35.

25. Sanchez L, Boyd C, Davis A. Prevalence and problems od tinnitus in the elderly. In: Proceedings of the Sixth International Seminar; 1999 Sep 5-9; Cambridge, UK. p.58-63.

26. Lindberg P, Scott B. The use of predictive value of psychological profiles in helpseeking and non-helpseeking tinnitus sufferers. In: Proceedings of the Sixth Internacional Seminar; 1999 Sep 5-9; Cambridge, UK. p.114-7.

27. Sibelle P, Vesterager V. Tinnitus from a psychological perspective. In: Proceedings of the Sixth Internacional Seminar; 1999 Sep 5-9; Cambridge, UK. p.575-76.

28. Mckenna L, Hallam R. A neuropsychological study of concentration problems in tinnitus patients. In: Proceedings of the Sixth Internacional Seminar; 1999 Sep 5-9; Cambridge, UK. p.108-13. 